\title{
A Review of Sex Determining Mechanisms in Geckos (Gekkota: Squamata)
}

\author{
T. Gamble \\ Department of Genetics, Cell Biology and Development, University of Minnesota, Minneapolis, Minn., USA
}

\section{Key Words}

Comparative method $\cdot$ Female heterogamety $\cdot$ Genetic sex determination - Homology • Lizard - Male heterogamety • Reptile $\cdot$ Sex chromosomes $\cdot$ Temperature-dependent sex determination

\begin{abstract}
Geckos are a species-rich clade of reptiles possessing diverse sex determining mechanisms. Some species possess genetic sex determination, with both male and female heterogamety, while other species have temperature-dependent sex determination. I compiled information from the literature on the taxonomic distribution of these sex determining mechanisms in geckos. Using phylogenetic data from the literature, I reconstructed the minimum number of transitions among these sex determining mechanisms with parsimony-based ancestral state reconstruction. While only a small number of gecko species have been characterized, numerous changes among sex determining mechanisms were inferred. This diversity, coupled with the high frequency of transitions, makes geckos excellent candidates as a model clade for the study of vertebrate sex determination and evolution.
\end{abstract}

Copyright $\odot 2010$ S. Karger AG, Basel

\section{KARGER}

Fax +4161306 1234

E-Mail karger@karger.ch

www.karger.com
(C) 2010 S. Karger AG, Basel

Accessible online at: www.karger.com/sxd
The near universal occurrence of sexual reproduction in animals suggests an ancient origin and predicts the presence of conserved sex determining mechanisms. As expected, many of the downstream elements in sex determining networks are conserved, with homologous genes performing similar roles in a wide variety of animal taxa. The regulatory switch that controls these conserved pathways, though, can exhibit incredible variety [Zarkower, 2001; Barske and Capel, 2008]. In vertebrates, the regulatory switch can be either genetic or environmental or, in some cases, both [Bull, 1983; Shine et al., 2002]. In species with genetic sex determination (GSD), the sex of the developing embryo is determined by genetic factors at fertilization. Within GSD species there are 2 primary sex determining systems. In some species, males are heterozygous for the master sex determining gene, this is the familiar XY system found in mammals. In other species, females are the heterogametic sex, this is the ZW system found in birds and snakes. Both systems can be thought of as a simple Mendelian model with 2 different alleles of the master sex determining gene. Homozygosity leads to the development of one sex while heterozygosity leads to the other. In species with environmental sex determination (ESD), environmental factors during embryonic development determine sex. Temperature is the most common environmental cue in tetrapods, a phenomenon

Tony Gamble

Department of Genetics, Cell Biology and Developmen University of Minnesota

Minneapolis, MN 55455 (USA)

Tel. +1 612626 4259, Fax +1 612626 6140, E-Mail gambl007@umn.edu 
known as temperature-dependent sex determination (TSD). The conservation of downstream mechanisms in the sex determining pathway makes the theoretical transition between GSD and TSD easy through simple changes in the master regulator. This could occur through some temperature sensitive mutation in a TSD species or the acquisition of a sex determining function of some autosomal gene in a GSD species. Understanding how different master regulators initiate gonadogenesis and how transitions occur among different sex determining mechanisms (SDMs) is an exciting, emerging field in evolutionary and developmental biology.

Transitions between different SDMs have occurred repeatedly in vertebrates [Hillis and Green, 1990; Janzen and Phillips, 2006; Mank et al., 2006; Organ and Janes, 2008]. Sister taxa at a variety of hierarchical taxonomic levels exhibit alternate sex determining modes. Crocodilians, for example, possess TSD while birds have GSD [Lang and Andrews, 1994]. The turtle family Carettochelidae possesses TSD while its sister group, the Trionychidae has GSD [Janzen and Phillips, 2006]. At the generic level, a master sex determining gene, DMY, has been identified in 2 Oryzias fish species, O. latipes and O.curvinotus [Matsuda et al., 2002, 2003; Nanda et al., 2002]. This gene is absent in 3 other species in the genus, O. luzonensis, O. hubbsi and O. mekongensis [Matsuda, 2005], which suggests that a different mechanism is responsible for sex determination in these species. Similarly, in the Japanese frog Rana rugosa, ZW sex chromosome systems have evolved from the ancestral XY system twice independently [Ogata et al., 2008]. While the exact mechanisms necessary to effect the transition between TSD and GSD are not yet well understood, judging from its frequency, the transition is assumed to be easy to accomplish [Janzen and Phillips, 2006; Mank et al., 2006].

The extreme plasticity of sex determining mechanisms and the ease with which transitions among sex determining mechanisms can occur is best exemplified by research conducted on the worm Caenorhabditis elegans [Hodgkin, 2002]. Typically, C. elegans possess 2 sexual phenotypes: males and self-fertilizing hermaphrodites, and sex is determined by the ratio of sex chromosomes to autosomes [Zarkower, 2001]. Hodgkin [2002] described mutations in a variety of genes that mimic the various sex determining mechanisms found in different animal species. Numerous autosomal loci were turned into master sex determining genes, thereby converting each of the 5 C. elegans autosomes into sex chromosomes. Several mutations mimicked TSD, one strain produced males at low incubation temperatures and hermaphrodites at high in- cubation temperatures, while a separate mutation produced the opposite pattern. The variety of gene types that Hodgkin [2002] recruited into the master sex determining role is also astounding and includes transmembrane receptors, transcription factors, a phosphatase, cytoplasmic proteins, a protease and a tRNA! It is readily apparent from this research that in nature almost any molecule could be recruited into becoming a master sex determining gene and that transitions among sex determining mechanisms are easy to accomplish.

Sex chromosomes evolve from autosomes [Muller, 1914; Ohno, 1967]. Evidence that a pair of sex chromosomes has a common ancestor comes from the presence of shared genes in the nonrecombining regions of the chromosomes, and has been found in the sex chromosomes of birds [Fridolfsson et al., 1998; Graves and Shetty, 2001], mammals [Graves and Shetty, 2001], snakes [Matsubara et al., 2006], and a gecko [Kawai et al., 2009]. Changing a pair of autosomes into sex chromosomes requires 2 provisions: the acquisition of a sex determining function and suppression of recombination. Gene loss can lead to a degradation of the nonrecombining, heterozygous region and may ultimately lead to the development of morphologically heteromorphic, chromosomes [Ohno, 1967; Charlesworth et al., 2005]. One prediction of this model is that sex chromosomes early in this process should be morphologically homomorphic, while older, more derived sex chromosomes should be morphologically heteromorphic [Ohno, 1967; Charlesworth et al., 2005]. It follows then that while the presence of morphologically heteromorphic sex chromosomes is a strong indicator of GSD in a species, the lack of heteromorphic sex chromosomes does not rule out the possibility of GSD, especially in species with newly evolved sex determining mechanisms [Valenzuela et al., 2003].

The tremendous variation in vertebrate sex determination presents an opportunity to understand fundamental processes involved in the evolution of sex determining mechanisms. Traditional model organisms, such as mice, have contributed considerably to our understanding of how master regulators initiate gonadogenesis in vertebrates. Unfortunately, a lack of diversity of sex determining mechanisms makes most mammals poor models for understanding the evolution of transitions among sex determining mechanisms. This emerging research requires, therefore, the development of new model systems that reflect the variation in sex determining mechanisms found in nature. Reptiles in particular have been identified as models to study sex determination and the evolution of different sex determining mechanisms 
(fig. 1) [Sarre et al., 2004; Janzen and Phillips, 2006]. Here, I discuss one of the most species-rich reptilian lineages, geckos, and their possible use as a model clade for the study of the evolution of sex determining mechanisms.

Geckos are a diverse clade of lizards consisting of over 1,300 described species comprising $14 \%$ of all reptile species [Uetz, 2009]. Geckos are geologically ancient, with origins in the Jurassic [Conrad and Norell, 2006], and are the sister taxon to the remaining lizards and snakes, exclusive of the limbless dibamids [Vidal and Hedges, 2009]. Geckos are quite amenable to studying questions related to sex determining mechanisms. Most importantly, they possess all of the major vertebrate sex determining mechanisms, including GSD with both male and female heterogamety, and TSD. The variation in sex chromosomes is itself amazing. Indeed, within the gekkota there are no documented genera where all the species are known to possess heteromorphic sex chromosomes and no examples of sister species sharing homologous heteromorphic sex chromosomes [Moritz, 1990]. Such exceptional reproductive diversity makes geckos an ideal group to examine the transitions between different reproductive modes. Here, I review current knowledge about gekkotan sex determining mechanisms, estimate the minimum number of transitions among sex determining systems in geckos and highlight the potential importance of geckos as models in the study of vertebrate sex determination.

\section{Gekkotan Sex Determining Mechanisms}

Geckos are currently divided into 7 families (fig. 2). Here, I summarize published information regarding sex determination and sex chromosomes for species in each gekkotan family.

\section{Carphodactylidae}

Nothing is known about the sex determining mechanisms of the Australian Carphodactylidae. Only 6 of 28 described species have been karyotyped, showing no evidence of heteromorphic sex chromosomes, and only one of these species, Underwoodisaurus milii has a published karyotype for both sexes [Matthey, 1933; King, 1987]. There are no data concerning the effects of incubation temperature on hatchling sex.

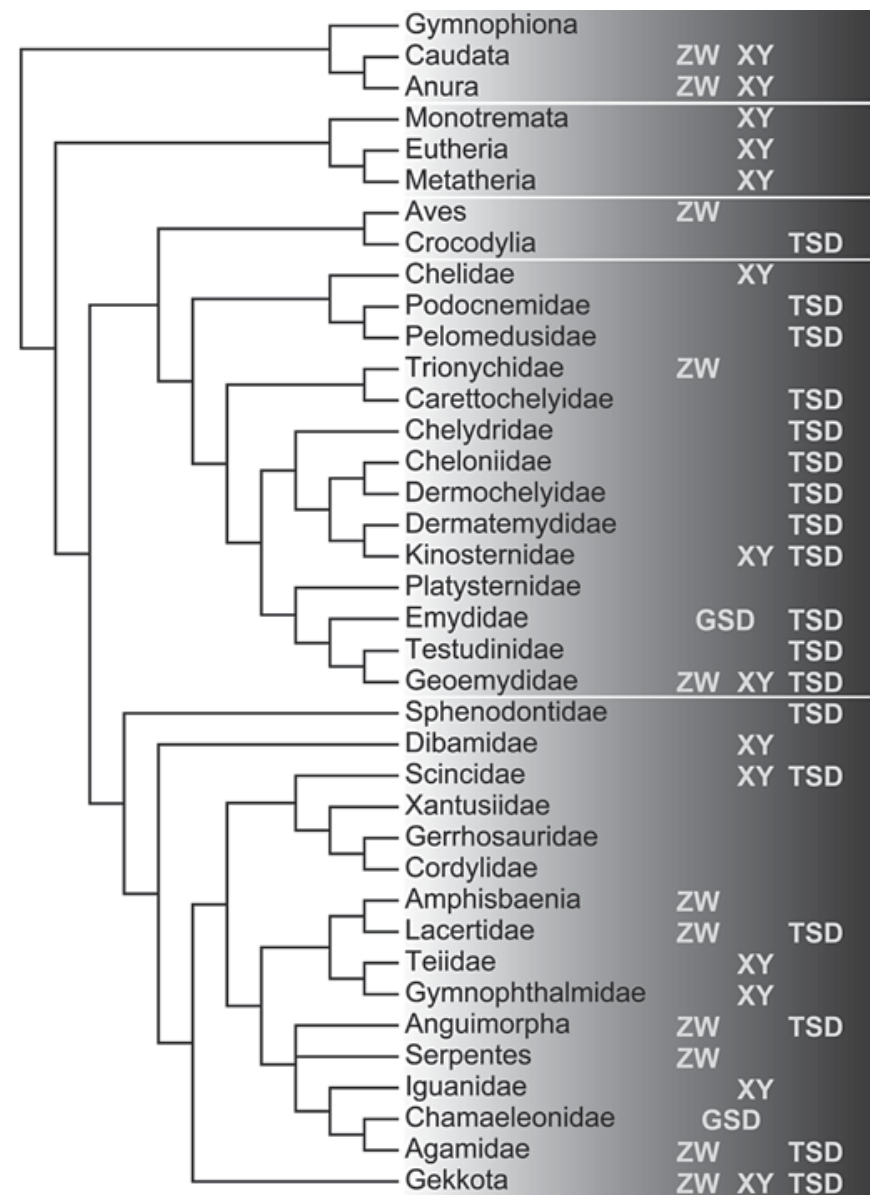

Fig. 1. Sex determining mechanisms in major tetrapod clades. XY indicates clade contains species with male heterogamety, ZW indicates clade contains species with female heterogamety, TSD indicates clade contains species with temperature dependent sex determination and GSD indicates clade contains species with genetic sex determination not associated with heteromorphic sex chromosomes. Phylogeny compiled from the following sources: tetrapods [Hugall et al., 2007]; turtles [Iverson et al., 2007]; squamates [Vidal and Hedges, 2009]. Sex determining mechanisms were taken from multiple sources, including recent reviews of vertebrate sex determining mechanisms [Hillis and Green, 1990; Harlow, 2004; Janzen and Krenz, 2004; Valenzuela, 2004; Andrews, 2005; Organ and Janes, 2008].

\section{Diplodactylidae}

Diplodactylidae occur throughout Australia, New Zealand and New Caledonia. While a large number of species have been karyotyped, there are no examples of heteromorphic sex chromosomes. There are some published data concerning hatchling sex ratios. For example, a balanced sex ratio, 8 males to 5 females, was reported 


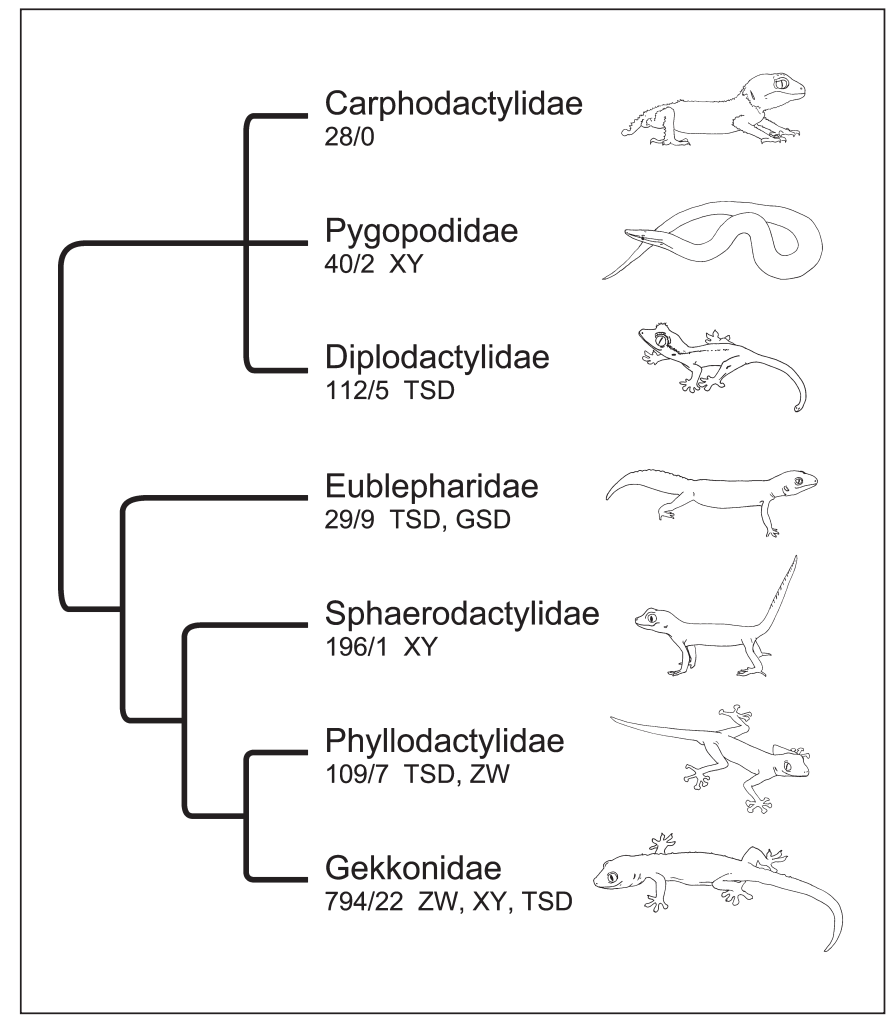

Fig. 2. Phylogenetic relationships among gekkotan families [Gamble et al., 2008b] showing the number of described species in each family followed by the number of species with known sex determining mechanism. The variety of sex determining mechanisms described for species in each family are also shown.

among hatchling Pseudothecadactylus lindneri at 29$33^{\circ} \mathrm{C}$ [Sonnemann, 1998]. There is some evidence that several of the New Caledonian Rhacodactylus species possess TSD [Seipp and Henkel, 2000; de Vosjoli et al., 2003]. Three species, R. auriculatus, $R$. leachianus and $R$. sarasinorum, have been karyotyped and show no heteromorphic sex chromosomes [King, 1987]. Rhacodactylus ciliatus, and R. leachianus produce a higher proportion of females at low incubation temperatures and a higher proportion of males at higher incubation temperatures [Seipp and Henkel, 2000; de Vosjoli et al., 2003]. There is conflicting information for R. auriculatus; Seipp and Henkel [2000] report more males at low incubation temperatures and more females at high incubation temperatures, while de Vosjoli et al. [2003] report the opposite pattern. Rhacodactylus sarasinorum produces more males at low incubation temperatures and more females at high incubation temperatures [Myers, 1997; Seipp and Henkel, 2000].
These incubation data are reported by hobbyists and breeders keeping geckos as pets and the number of individuals hatched out at different temperatures is not reported. This lack of quantitative data makes even simple statistical comparisons impossible. Large numbers of clutches are necessary when performing incubation experiments as most gecko species have a fixed clutch size of 2 eggs [Kluge, 1987]. Rhacodactylus are popular in the pet trade so it should not be difficult to perform rigorous incubation experiments to better understand the sex determining mechanisms of these geckos.

\section{Eublepharidae}

Sex determining mechanisms are well characterized for several species of Eublepharidae, most notably TSD in the leopard gecko, Eublepharis macularius. TSD was first described in E. macularius as a pattern with females being produced at low incubation temperatures and males at high incubation temperatures [Thorogood and Whimster, 1979; Wagner, 1980a, b; Bull, 1987], a pattern known as Type Ib TSD [Ewert and Nelson, 1991]. Additional incubation experiments at a wider range of temperatures eventually confirmed that E. macularius possessed Type II TSD [Viets et al., 1993], with females produced at both high and low incubation temperatures and males produced at intermediate temperatures.

Incubation temperature influences more than just sex in E. macularius. Several experiments, designed to uncouple incubation temperature from sex, often through the application of exogenous hormones to the embryo, have provided unique insights into phenotypic traits other than sex that are regulated by incubation temperature. Head size, for example, is typically larger in males than in females, although females incubated at male-biased temperatures have wider heads than females produced at female-biased temperatures [Crews, 1998]. Incubation temperature also affects growth rate, blood hormone levels, and breeding behavior [Flores et al., 1994; Tousignant and Crews, 1995; Coomber et al., 1997]. The linkage of temperature and phenotype is a prerequisite for the hypotheses that TSD persists when incubation temperature differentially affects male and female fitness and suggests geckos may be appropriate models to test these hypotheses [Charnov and Bull, 1977; Rhen and Lang, 1995; Shine, 1999].

Eublepharis macularius is the only gecko species with published data on gene expression in the sex determining pathway. $S O X 9$, a transcription factor crucial to testis de- 
velopment in a variety of vertebrates [Western and Sinclair, 2001; Chaboissier et al., 2004] is expressed in urogenital tissues from both male and female E. macularius up to the temperature-sensitive period. After the temperature-sensitive period, SOX9 is expressed only in male urogenital tissues [Valleley et al., 2001]. The apparent conservation of $S O X 9$ as a testis-determining factor in a gecko provides support for the functional conservation of downstream elements in the sex determining pathway [Zarkower, 2001].

TSD is known from several other eublepharid genera as well. TSD is well documented in the West African Hemitheconyx caudicinctus [Wagner, 1980a; Anderson, 1993; Viets et al., 1994]. Like E. macularius, this species exhibits Type II pattern TSD [Viets et al., 1994]. The East African genus Holodactylus is poorly known and not frequently bred in captivity. One might suspect, given its phylogenetic proximity to other TSD species, that it might also possess TSD. Sex ratio data suggests temperature may influence hatchling sex in several Goniurosaurus species [Seufer et al., 2005]. Seufer et al. [2005] report on incubating over 160 eggs from 6 Goniurosaurus species. Most eggs, 94, were from G. splendens. Eggs were incubated at fluctuating temperatures $\left(26-28^{\circ} \mathrm{C}\right)$ with a nighttime temperature drop $\left(25-26^{\circ} \mathrm{C}\right)$. Over $80 \%$ of $G$. orientalis, G. splendens and G. kuroiwae hatchlings were females. An even sex ratio was produced from the remaining species, G. araneus and G. luii with $50 \%$ females and $G$. lichtenfelderi with $60 \%$ females, which is consistent with either TSD or GSD. Equal hatchling sex ratios in $G$. araneus, G. luii and G. lichtenfelderi could, if these species possess TSD, be the result of incubation temperatures near the pivotal temperature. The skewed sex ratios in G. orientalis, G. splendens and G. kuroiwae, incubated at the same temperatures, may reflect a shift in pivotal temperature between the 2 groups of species. Pivotal temperatures of TSD species are known to change with latitude [Bull et al., 1982; Ewert et al., 2005]. Goniurosaurus species occur over a wide latitudinal gradient with G. araneus, G. luii and G. lichtenfelderi occurring in Northern Vietnam, Southeast China, and Hainan, while G. orientalis, G. splendens and G. kuroiwae occur farther North in the Ryukyu Islands. With a lower pivotal temperature, the Northern species would presumably be incubating in female-biased temperatures while Southern species remain near their pivotal temperature. Controlled incubation experiments are necessary to rigorously test this hypothesis but the data presented by Seufer et al. [2005] are compelling.
The New World genus Coleonyx is the sister taxon to the Old World clade containing Eublepharis, Hemitheconyx, Holodactylus and Goniurosaurus [Grismer, 1988]. There is no evidence of heteromorphic sex chromosomes in 2 species that have been karyotyped, C. switaki and C. variegatus [Gorman, 1973; Murphy, 1974]. Four species show balanced sex ratios at a variety of incubation temperatures, which suggests a genetic sex determining mechanism [Viets et al., 1994; Bragg et al., 2000; Kratochvil et al., 2008].

The change in sex determining mechanism between GSD in Coleonyx and TSD in the clade containing Goniurosaurus, Eublepharis and Hemitheconyx provides an excellent opportunity to study a transition in sex determining system. Many studies have found value in comparing TSD and GSD species [Sarre et al., 2004; Shine et al., 2007; Valenzuela and Shikano, 2007; Valenzuela, 2008]. Here is an example where the 2 systems are each other's closest relatives. Indeed, several factors contribute to the exceptional nature of this model including: a robust phylogeny for the group [Grismer, 1988; Grismer et al., 2002]; several species are amenable to captivity and prolific breeders [Seufer et al., 2005]; and 1 species, E. macularius, is well characterized and an emerging model in the study of reptilian TSD [Crews, 1998; Shoemaker and Crews, 2009]. Ideally, one could verify the directionality of the shift (e.g. TSD to GSD or GSD to TSD) in sex determining mechanism and search for correlates to the change and the subsequent maintenance of the system. A transition to GSD in Coleonyx from a TSD ancestor has been implied in some phylogenetic ancestral state reconstruction [Pokorna and Kratochvil, 2009] although the ancestral state is equivocal in other analyses [Janzen and Phillips, 2006; Pokorna and Kratochvil, 2009]. Inclusion of Aeluroscalabotes felinus, the sister species to the remaining Eublepharidae [Grismer, 1988], would likely aid in the resolution of that transition. A high priority, therefore, should be placed on assessing the sex determining mechanism of A. felinus. TSD has been implied, but there were no data provided and hatchlings from just 10 eggs were examined [Lui, 1996].

\section{Gekkonidae}

Gekkonidae are the largest gekkotan family with almost 800 described species. Although sex determining mechanisms are known for only a fraction of the species there is exceptional diversity in the sex determining mechanisms that are known. 


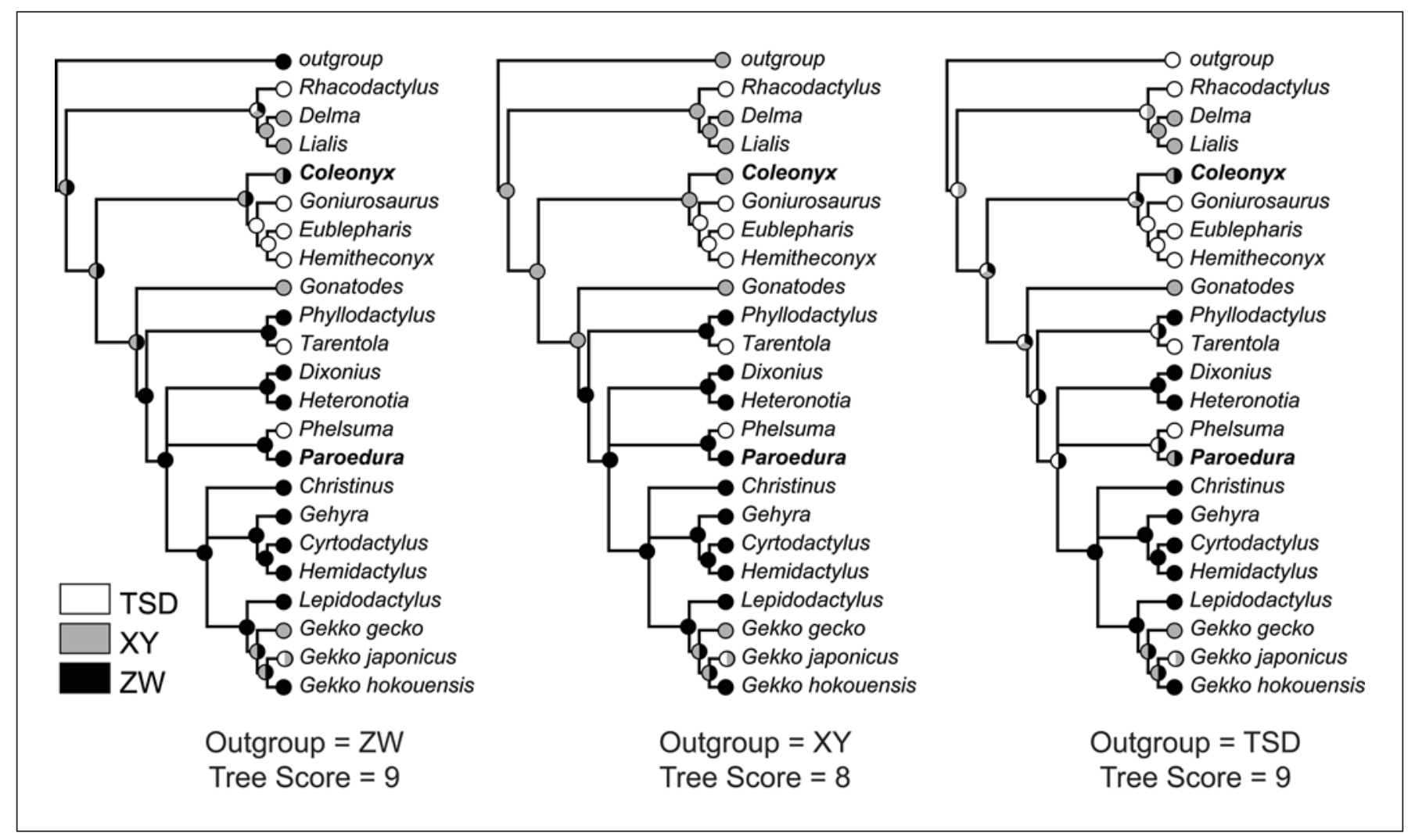

Fig. 3. Ancestral state reconstructions of gekkotan sex determining mechanisms using parsimony. Phylogeny was reconstructed using the supertree method from 7 published phylogenies. Species were assigned to 3 sex determining mechanisms: Temperature dependent sex determination (TSD), male heterogamety (XY), and female heterogamety $(\mathrm{ZW})$. The ancestral condition of the out- group was coded as a different character state in each of 3 analyses. Polymorphic states are shown as multi-colored circles. Coleonyx and Paroedura are shown in bold. These 2 genera were coded as either ZW or XY and their sex determining mechanisms were estimated as part of the analysis.
The Australo-Pacific genus Gehyra has been the subject of numerous chromosomal studies. Three forms show evidence of a ZW sex determining mechanism. Female heterogamety was observed in some Northern populations of Gehyra australis [King, 1983]. Female heterogamety was also observed in a population of Gehyra cf. nana from the MacDonnell ranges in central Australia [Moritz, 1986]. Gehyra purpurascens possesses a ZW sex determining system with 6 distinct $\mathrm{W}$ chromosome patterns distributed within and among populations across the eastern portion of G. purpurascens range [Moritz, 1984a]. There is some evidence that the sex chromosomes in these 3 species are homologous and derived from the same autosomal pair [Moritz, 1990].

Several species of Lepidodactylus have been karyotyped, most notably the parthenogenetic Lepidodactylus lugubris. The largest chromosomal pair in the L. lugubris karyotype was heteromorphic in both size and banding [Volobouev and Pasteur, 1988]. This was assumed to be a case of female heterogamety. The possession of a ZW system in L. lugubris offers the best explanation for the occasional male specimens that occur since it is conceivable that the ZZ complement could be reconstituted from a ZW individual [Volobouev and Pasteur, 1988; Röll and von Düring, 2008]. In contrast, if L. lugubris possessed male heterogamety, with XX females, there is no way an $\mathrm{XY}$ individual could be spontaneously produced. Parthenogenesis in vertebrates is thought to occur through apomixis or premeiotic endomitosis [Dawley, 1987] where diploid ova produce viable young without the contribution of sperm. Premeiotic endomitosis occurs in parthenogenetic taxa of hybrid origin such as the lizard Aspidoscelis uniparens [Cuellar, 1971] and hybrid Medaka fish (genus Oryzias) [Shimizu et al., 1997] and is presumed to 
be the primary means of reproduction in parthenogenetic geckos [Röll and von Düring, 2008].

The genus Gekko is perhaps one of the most interesting gekkotan genera with regard to sex determining mechanisms. Many species have been karyotyped and 3 species, G. gecko, G. japonicus and G. hokouensis, possess heteromorphic sex chromosomes [Yoshida and Itoh, 1974; Solleder and Schmid, 1984; Kawai et al., 2009]. Gekko gecko has an XY sex determining mechanism [Solleder and Schmid, 1984] although this species had been karyotyped several times before with no observed heteromorphic sex chromosomes [Cohen et al., 1967; De Smet, 1981; Wu and Zhao, 1984]. The failure to observe heteromorphic sex chromosomes in the previous studies is certainly related to the banding techniques used by Solleder and Schmid [1984] but could also be due to the presence of cryptic, undescribed species. While there has yet to be a comprehensive review of G. gecko across its range, preliminary evidence suggests several cryptic lineages within G. gecko [Qin et al., 2007]. The largely equal amounts of heterochromatin observed on the X and Y chromosomes led Solleder and Schmid [1984] to suggest that the sex chromosomes of G. gecko were at an early stage of differentiation. This seems very plausible when examined in a phylogenetic context (fig. 3) although data from additional species of Gekko are clearly needed to confirm this. Interestingly, the Y chromosome of G. gecko was larger than the $\mathrm{X}$ chromosome, a condition also found in G. japonicus [Yoshida and Itoh, 1974].

Individuals of Gekko japonicus have been karyotyped several times [Nakamura, 1932; Yoshida and Itoh, 1974; Chen et al., 1986]. Yoshida and Itoh [1974] found evidence of heteromorphic sex chromosomes in the male G. japonicus karyotyped, where the $\mathrm{X}$ was the smallest telocentric chromosome and the $\mathrm{Y}$ a larger acrocentric chromosome. Chen et al. [1986] found a very different karyotype in G. japonicus from Eastern China, with no evidence of heteromorphic sex chromosomes. The differences between the 2 populations could indicate the presence of a cryptic species.

Incubation experiments of G. japonicus indicate it possesses TSD [Tokunaga, 1985]. The co-occurrence of heteromorphic sex chromosomes and TSD in G. japonicus is intriguing although the data come from 2 separate studies and should be viewed cautiously. Yoshida and Itoh [1974] karyotyped 1 male and 1 female G. japonicus from an unknown locality. Tokunaga [1985] collected G. japonicus from Fukuoka City, Kyushu for his incubation experiments. One critique is that the geckos used in the 2 studies were different, cryptic species [Sarre et al., 2004].
This is possible, as several new species of Gekko have recently been described from the islands of southern Japan [Toda et al., 2001, 2009]. Widespread hybridization in southern Japan between G. japonicus and the closely related G. tawaensis [Toda et al., 2006] further complicates matters. Assuming the geckos in question were indeed the same species, the co-occurrence of heteromorphic sex chromosomes and TSD in G. japonicus would add further evidence to the hypothesis that TSD and GSD are extremes of a continuum, not discrete states [Shine et al., 2002; Sarre et al., 2004]. Unfortunately, the lack of voucher specimens and a failure to note the collecting locality, in the case of the Yoshida and Itoh [1974] paper, makes this problem intractable. Resolution will likely require a repetition of the experiments with geckos from the same locality.

The problems associated with interpreting the disparate results of these $2 \mathrm{G}$. japonicus studies highlight the need for vouchers in sex determination research. Accurate identification of the species being examined is crucial for any comparative work. In this case, the inability to verify species identification made interpreting the results impossible since the disparities can be dismissed simply as differences between species. Several steps can be taken to avoid confusion like this from occurring in the future. First, vouchers of karyotyped individuals should be deposited in public museums so other scientists can examine them and verify identification. Second, karyotyped animals should be genotyped and have genetic sequences submitted to a public database such as GenBank, EMBL or DDBJ. Investigators can simply sequence a fragment of a mitochondrial gene and follow basic guidelines like those set up for DNA barcoding [Tautz et al., 2003; Vences et al., 2005]. Implementing one or, ideally, both of these practices would go a long way toward reducing the confusion that can result from a lack of confidence in species identification.

Kawai et al. [2009] karyotyped G. hokouensis from Okinawa, Japan. They examined 9 individuals from each sex and described heteromorphic sex chromosomes in the females. The sex chromosomes in the Okinawa $G$. hokouensis both possessed the same complement of 6 genes as determined by fluorescent in situ hybridization (FISH) suggesting they are in an early stage of differentiation. The absence of heteromorphic sex chromosomes in G. hokouensis specimens from eastern China [Chen et al., 1986] supports this hypothesis. FISH results supported the homology between the sex chromosomes of $G$. hokouensis and the sex chromosomes of birds [Kawai et al., 2009]. 
Species in the genus Phelsuma occur on Madagascar and other Indian Ocean islands as well as one species on the East coast of Africa. Eight species have been karyotyped with no evidence of heteromorphic sex chromosomes [Aprea et al., 1996]. Several species show evidence of TSD. Phelsuma grandis and P. dubia both produce females at low incubation temperatures and males at high incubation temperatures [Osadnik, 1987; Viets et al., 1994]. Phelsuma guimbeaui produced no males at a range of incubation temperatures [Tytle, 1994; Viets et al., 1994] although males are known to occur in this species and are required for reproduction [McKeown, 1989]. Several other Phelsuma species, $P$. pusilla, P. guentheri, P. laticauda, and $P$. madagascariensis, are suspected as having TSD although the data are minimal and far from conclusive [Bloxam and Tonge, 1980; Howard, 1980; Viets et al., 1994]. Other species, P. kochi, P. cepediana, P. ornata and $P$. sundbergi, show balanced hatchling sex ratios consistent with either TSD or GSD [Viets et al., 1994].

The genus Lygodactylus is closely related to Phelsuma [Austin et al., 2004]. Only 1 species, L. picturatus, has been karyotyped [Castiglia, 2004]. Castiglia [2004] reported $2 \mathrm{n}=40$ in the male karyotype but a variable number of chromosomes in the female, $2 \mathrm{n}=41$ in 18 mitotic spreads, $2 \mathrm{n}=40$ in 4 spreads, and $2 \mathrm{n}=39$ in 2 spreads. There are several possible reasons for this disparity in diploid number between male and female specimens. It is possible that the 6 cells with $2 \mathrm{n}$ less than 41 were the result of some technical inaccuracy. It is also possible that the additional chromosomes may be supernumerary or B chromosomes. Castiglia [2004] also mentioned the possibility of an OW sex determining system, similar to the sex chromosomes of the frog Leiopelma hochstetteri [Green, 1988], where females possess a characteristic supernumerary chromosome that behaves as a sex chromosome. Additional L. picturatus specimens should be examined to verify the presence of this unique sex chromosome mechanism.

The Malagasy species Paroedura picta shows balanced sex ratios at a range of incubation temperatures [Blumberg et al., 2002; Kratochvil et al., 2008]. This pattern is consistent with GSD.

Populations of Cyrtodactylus pubisulcus from western Sarawak, Malaysia possessed a ZW sex determining system [Ota et al., 1992]. Several other Cyrtodactylus species have been karyotyped with no evidence of heteromorphic sex chromosomes [Ota et al., 1992].

The triploid, parthenogenetic species Hemidactylus vietnamensis possessed a fixed heteromorphism at chromosome 3 [Darevsky et al., 1984]. This is consistent with the female heterogamety reported in other parthenogenetic gecko species, e.g. Heteronotia binoei [Moritz, 1984b] and Lepidodactylus lugubris [Volobouev and Pasteur, 1988]. Hemidactylus mabouia was reported as having GSD [Pokorna and Kratochvil, 2009] and the authors cited McBee et al. [1987] as the source. This is in error, McBee et al. [1987] make no mention of GSD in the manuscript and state that $H$. mabouia possessed no heteromorphic sex chromosomes.

One population of the Asian leaf-toed gecko, Dixonius siamensis from Northern Thailand, possessed a ZW sex determining system [Ota et al., 2001]. Individuals from 3 other populations showed no evidence of heteromorphic sex chromosomes. Recent phylogenetic analyses indicate a close relationship among the genera Dixonius, Nactus and Heteronotia [Jackman et al., 2008]. There is no evidence of heteromorphic sex chromosomes in any of the Nactus species studied to date but, like Heteronotia, there are several parthenogenetic lineages [Moritz, 1987; Donnellan and Moritz, 1995].

The Australian genus Heteronotia consists of 3 described species, one of which, $H$. binoei, is a complex of diploid sexual lineages and 2 triploid, parthenogenetic lineages [Moritz, 1983, 1990; Strasburg and Kearney, 2005]. Several of the different lineages possessed heteromorphic sex chromosomes with female heterogamety [Moritz et al., 1990]. Mapping the sex chromosomes onto a phylogeny, Moritz [1990] inferred that heteromorphic sex chromosomes evolved multiple times independently from a homomorphic ancestor. Additionally, the different sex chromosome variants were easily distinguishable among each other based on C-banding. The multiple origins and large number of $\mathrm{W}$ chromosome variants make Heteronotia an excellent group to study sex chromosome evolution within Gekkota.

\section{Phyllodactylidae}

Several species of Phyllodactylidae have been karyotyped and one species, Phyllodactylus lanei from Guerrero, Mexico, showed evidence of heteromorphic sex chromosomes [King, 1991]. Recently, the identification of King's specimens has been called into question [Castiglia et al., 2009]. Castiglia et al. [2009] karyotyped several individuals, from both sexes, of $P$. lanei from Jalisco, Mexico. They found no evidence of heteromorphic sex chromosomes in their specimens. The differences between the 2 studies are very likely due to the examination of different species. Three other Phyllodactylus species occur 
in Guerrero in addition to P. lanei, they are: P. tuberculosus, P. delcampoi and P. boardi [Dixon, 1964]. It is possible that King [1991] examined one of these species. It is also possible that differences between the 2 studies resulted from geographic variation among populations of $P$. lane $i$, particularly since there are several described subspecies [Dixon, 1964; Castro-Franco and Uribe-Pena, 1992]. Regardless of the exact cause of the discrepancy, like the previously mentioned problems with Gekko japonicus, the inability to verify specimen identification hampers the comparative value of the results.

The North African genus Tarentola has several species that show evidence of TSD [Nettmann and Rykena, 1985]. Nettmann and Rykena [1985] hatched 81 juveniles from 6 Tarentola species and all of the hatchlings were females. The majority of the eggs were from just 2 species, 33 juvenile T. mauritanica and 23 T. b. hierrensis. Eggs were incubated at temperatures between $27-30^{\circ} \mathrm{C}$, either at a constant temperature within this range or with daily fluctuations between these 2 temperatures. None of the Tarentola species that have been karyotyped show evidence of heteromorphic sex chromosomes [De Smet, 1981; Odierna et al., 1994].

\section{Pygopodidae}

Male heterogamety is claimed for most of the snakelike Pygopodidae although much of this data remains unpublished [King, 1990]. Delma inornata has an XY system [King, 1990] while Lialis burtonis has an XXY system [Gorman and Gress, 1970].

\section{Sphaerodactylidae}

Sphaerodactylidae are a species-rich family consisting of 196 species. Almost nothing is known about the sex determining mechanisms in this family and just 1 species, Gonatodes ceciliae, shows evidence of heteromorphic sex chromosomes. There are no published accounts concerning the effects of incubation temperature on the sex of hatchlings from any sphaerodactylid species.

Six species of Gonatodes have published karyotypes. Only 2 of these species, G. humeralis and G. hasemani have karyotypes from both sexes [dos Santos et al., 2003] and, as mentioned above, only 1 species, Gonatodes ceciliae, possessed heteromorphic sex chromosomes. Evidence for heteromorphic sex chromosomes comes from 2 male G. ceciliae, captured from the same locality in Trin- idad [McBee et al., 1987]. Interestingly, both individuals had a different number of diploid chromosomes, $2 \mathrm{n}=22$ and $2 n=26$. For now it is difficult to determine if this is the result of intraspecific chromosomal variation, cryptic, sympatric species, or error in karyotyping. Gonatodes vittatus was reported as having GSD [Pokorna and Kratochvil, 2009] and the authors cited McBee et al. [1987] as the source. This is clearly in error, McBee et al. [1987] make no mention of GSD in the study and state that G. vittatus possessed no heteromorphic sex chromosomes.

Several species of Teratoscincus have been karyotyped with no reported heteromorphic sex chromosomes [Manilo, 1993; Zeng et al., 1998]. The 2 remaining species in Sphaerodactylidae that have been karyotyped involved just single individuals, a female Coleodactylus amazonicus, and a male Pristurus carteri, no heteromorphic chromosome pairs were reported for either species [Branch, 1980; dos Santos et al., 2003].

\section{Evolution of Gekkotan Sex Determining Mechanisms}

Geckos hold great promise as a model clade for the study of vertebrate sex determination. Geckos are one of only 2 tetrapod clades possessing both male and female heterogamety along with TSD (fig. 1). Moreover, these sex determining mechanisms occur repeatedly across the phylogeny (fig. 2). To take full advantage of the potential that geckos hold as a model clade and to fully understand the processes involved in how transitions between sex determining mechanisms occur, requires knowledge of the pattern and distribution of these mechanisms in a phylogenetic context. To do this, I mapped sex determining mechanisms onto the gekkotan phylogeny to estimate the potential number of transitions in sex determining mechanism in geckos and to identify where transitions occur on the phylogeny. A complete, generic-level phylogeny is not yet available for geckos, therefore I used a 'supertree' approach to estimate phylogenetic relationships among gekkotan lizards. I used 7 published phylogenies as source trees [Grismer, 1988; Donnellan et al., 1999; Han et al., 2004; Melville et al., 2004; Gamble et al., 2008a, b; Jackman et al., 2008]. Non-gekkotan outgroups were collapsed into a single taxon, 'outgroup'. Matrix representation with parsimony (MRP) matrices were constructed using r8s [Sanderson, 2006] and analyzed using maximum parsimony with the heuristic search option in PAUP* 4.0b10 [Swofford, 2002] and Maxtrees set to 1,000. I used a conservative approach in summarizing results 
Table 1. Known examples of sex chromosomes in gekkotan lizards as determined by cytogenetic analyses

\begin{tabular}{|c|c|c|c|c|}
\hline Species & Family & $\begin{array}{l}\text { Chromosome } \\
\text { number }\end{array}$ & $\begin{array}{l}\text { Sex chromo- } \\
\text { somes }\end{array}$ & Source \\
\hline Christinus $m$. alexanderi & G & 36 & ZW & King and Rofe, 1976 \\
\hline Christinus m. marmoratus & G & 34 & ZW & King and Rofe, 1976 \\
\hline Christinus m. marmoratus & G & 32 & ZW & King and King, 1977 \\
\hline Cyrtodactylus pubisulcus & G & 42 & ZW & Ota et al., 1992 \\
\hline Dixonius siamensis & G & 42 & ZW & Ota et al., 2001 \\
\hline Gehyra australis & G & 40 & ZW & King, 1983 \\
\hline Gehyra cf. nana & G & 44 & ZW & Moritz, 1986 \\
\hline Gehyra purpurascens & G & 40 & ZW & Moritz, 1984a \\
\hline Gekko gecko & G & 38 & $\mathrm{XY}$ & Solleder and Schmid, 1984 \\
\hline Gekko hokouensis & G & 38 & $\mathrm{ZW}$ & Kawai et al., 2009 \\
\hline Gekko japonicus & G & 38 & $\mathrm{XY}$ & Yoshida and Itoh, 1974 \\
\hline Hemidactylus vietnamensis 'triploid' & G & 60 & ZW & Darevsky et al., 1984 \\
\hline Heteronotia binoei & G & 42 & $\mathrm{ZW}$ & Moritz, 1984b; Moritz et al., 1990 \\
\hline Heteronotia binoei 'triploid' & G & 63 & $\mathrm{ZW}$ & Moritz, 1984b \\
\hline Lepidodactylus lugubris & G & 44 & $\mathrm{ZW}$ & Volobouev and Pasteur, 1988 \\
\hline Lygodactylus picturatus & G & $39,40,41$ & OW? & Castiglia, 2004 \\
\hline Delma inornata & $\mathrm{P}$ & 36 & $\mathrm{XY}$ & King, 1990 \\
\hline Lialis burtonis & $\mathrm{P}$ & 33,34 & XXY & Gorman and Gress, 1970 \\
\hline Phyllodactylus cf. lanei & $\mathrm{Ph}$ & 34 & $\mathrm{ZW}$ & King, 1991 \\
\hline Gonatodes ceciliae & $\mathrm{S}$ & 22,26 & $\mathrm{XY}$ & McBee et al., 1987 \\
\hline
\end{tabular}

Family names are abbreviated: $\mathrm{G}=$ Gekkonidae, $\mathrm{P}=$ Pygopodidae, $\mathrm{Ph}=$ Phyllodactylidae; $\mathrm{S}=$ Sphaerodactylidae. Chromosome number is $2 \mathrm{n}$ for all species except 2 labeled triploid species that are $3 \mathrm{n}$. Note that only some Gehyra australis populations possess heteromorphic sex chromosomes [King, 1983].

using a (90\%) majority-rule consensus tree of the 1,000 saved, equally parsimonious trees. Non-focal taxa were pruned from the consensus tree for subsequent ancestral state reconstructions.

Several taxa of interest were not included in the original phylogenies and were added manually, post-hoc. Gekko japonicus and Gekko hokouensis are considered closely related to each other [Zhou et al., 1989; Han et al., 2001] and, together, were added as the sister group to Gekko gecko. No exemplars of Cyrtodactylus were included in the source trees as well. Molecular data suggests a close relationship between Cyrtodactylus and Hemidactylus [Bauer et al., 2008], therefore I placed Cyrtodactylus as the sister taxon to Hemidactylus. Lygodactylus picturatus was excluded from the analyses given the tentative nature of its assignment to a female heterogametic system [Castiglia, 2004].

I mapped sex determining mechanisms onto the gekkotan phylogeny using unordered parsimony [Fitch, 1971] in the program MacClade [Maddison and Maddison, 1992]. Parsimony was preferred over maximum likelihood and Bayesian reconstruction methods because it allows polymorphic character states and does not require branch length estimates. Polymorphic characters were especially important when including Coleonyx and Paroedura. Species in both genera possess GSD, as shown through incubation experiments, but there is either no evidence of heteromorphic sex chromosomes, e.g. Coleonyx, or no published karyotype, e.g. Paroedura. Coding GSD as a distinct character state, in addition to TSD, $\mathrm{XY}$ and ZW, to account for this lack of data [Janzen and Krenz, 2004; Pokorna and Kratochvil, 2009] does not necessarily resolve the issue. GSD species, such as $\mathrm{Co}$ leonyx and Paroedura are assumed to have either male or female heterogamety. These taxa can be coded as having either one of these states using the parsimony criterion. Coding these taxa as polymorphic avoids the ambiguity of introducing an additional character state and, depending on the character states of related taxa, has the added benefit of potentially resolving the sex determining mechanism for that species, providing a testable hypothesis for future cytogenetic research.

Included species were assigned to one or more character states based on data from the literature summarized in tables 1 and 2. Taxa were designated as having TSD, 
Table 2. Known examples of sex determining mechanisms in gekkotan lizards as determined by incubation experiments

\begin{tabular}{|c|c|c|c|}
\hline Species & Family & $\begin{array}{l}\text { Sex determining } \\
\text { mechanism }\end{array}$ & Source \\
\hline Rhacodactylus auriculatus & $\mathrm{D}$ & TSD & Seipp and Henkel, 2000; de Vosjoli et al., 2003 \\
\hline Rhacodactylus chahoua & $\mathrm{D}$ & TSD & Seipp and Henkel, 2000; de Vosjoli et al., 2003 \\
\hline Rhacodactylus ciliatus & $\mathrm{D}$ & TSD & Seipp and Henkel, 2000; de Vosjoli et al., 2003 \\
\hline Rhacodactylus leachianus & $\mathrm{D}$ & TSD & Seipp and Henkel, 2000; de Vosjoli et al., 2003 \\
\hline Rhacodactylus sarasinorum & $\mathrm{D}$ & TSD & Myers, 1997; Seipp and Henkel, 2000 \\
\hline Coleonyx brevis & $\mathrm{E}$ & GSD & Viets et al., 1994 \\
\hline Coleonyx elegans & $\mathrm{E}$ & GSD & Kratochvil et al., 2008 \\
\hline Coleonyx mitratus & $\mathrm{E}$ & GSD & Bragg et al., 2000 \\
\hline Coleonyx variegatus & $\mathrm{E}$ & GSD & Viets et al., 1994 \\
\hline Eublepharis macularius & $\mathrm{E}$ & TSD & Wagner, 1980b; Viets et al., 1993 \\
\hline Goniurosaurus kuroiwae & $\mathrm{E}$ & TSD & Seufer et al., 2005 \\
\hline Goniurosaurus orientalis & $\mathrm{E}$ & TSD & Seufer et al., 2005 \\
\hline Goniurosaurus splendens & $\mathrm{E}$ & TSD & Seufer et al., 2005 \\
\hline Hemitheconyx caudicinctus & $\mathrm{E}$ & TSD & Viets et al., 1994 \\
\hline Gekko japonicus & G & TSD & Tokunaga, 1985 \\
\hline Paroedura picta & G & GSD & Blumberg et al., 2002 \\
\hline Phelsuma dubia & G & TSD & Osadnik, 1987; Viets et al., 1994 \\
\hline Phelsuma grandis & G & TSD & Viets et al., 1994 \\
\hline Phelsuma guentheri & G & TSD & Viets et al., 1994 \\
\hline Phelsuma guimbeaui & G & TSD & Viets et al., 1994 \\
\hline Phelsuma laticauda & G & TSD & Viets et al., 1994 \\
\hline Phelsuma madagascariensis & G & TSD & Viets et al., 1994 \\
\hline Phelsuma pusilla & G & TSD & Viets et al., 1994 \\
\hline Tarentola angustimentalis & $\mathrm{Ph}$ & TSD & Nettmann and Rykena, 1985 \\
\hline Tarentola annularis & $\mathrm{Ph}$ & TSD & Nettmann and Rykena, 1985 \\
\hline Tarentola boettgeri hierrensis & $\mathrm{Ph}$ & TSD & Nettmann and Rykena, 1985 \\
\hline Tarentola delalandii & $\mathrm{Ph}$ & TSD & Nettmann and Rykena, 1985 \\
\hline Tarentola gomerensis & $\mathrm{Ph}$ & TSD & Nettmann and Rykena, 1985 \\
\hline Tarentola mauritanica & $\mathrm{Ph}$ & TSD & Nettmann and Rykena, 1985 \\
\hline
\end{tabular}

Family names are abbreviated: $\mathrm{D}=$ Diplodactylidae, $\mathrm{E}=$ Eublepharidae, $\mathrm{G}=$ Gekkonidae $\mathrm{Ph}=$ Phyllodactylidae. Sex determining mechanisms are labeled as either TSD, temperature dependent sex determination, or GSD, genetic sex determination.

male heterogamety (XY) or female heterogamety (ZW). As mentioned, Coleonyx and Paroedura were constrained to having either XY or ZW mechanism and Gekko japonicus coded as having XY and TSD.

Outgroups can have a dramatic impact on ancestral state reconstructions [Maddison et al., 1984; Cunningham et al., 1998]. I explored the influence of the outgroup's ancestral character state on reconstructing gekkotan sex determining mechanisms by performing the analysis 3 times with the ancestral state of the outgroup coded as either TSD, male heterogamety or female heterogamety. All 3 character states, alone or as a polymorphism, have been hypothesized as the ancestral sex determining mechanism of Unidentata, the sister clade to
Gekkota [Janzen and Krenz, 2004; Organ and Janes, 2008; Pokorna and Kratochvil, 2009].

Results of the ancestral state reconstruction are shown in figure 3. Phylogenetic character mapping suggests a minimum of 8 to 9 transitions among sex determining mechanisms in geckos! Treelength and the number of ambiguous ancestral nodes were minimized when the outgroup was coded as male heterogamety. Male heterogamety was reconstructed as the ancestral gekkotan sex determining mechanism with TSD evolving 5 times independently from a GSD ancestor, including the TSD in Gekko japonicus. Coleonyx was unambiguously assigned to a male heterogametic sex determining mechanism and Paroedura to a female heterogametic sex determining 
mechanism. An XY sex determining system was reconstructed as the ancestral gekkotan sex determining mechanism by Organ and Janes [2008] who also recovered an XY system as the ancestral sex determining system of the Unidentata, my hypothetical outgroup.

When female heterogamety was the ancestral sex determining system of the outgroup, a system that has not on its own been recovered as the sole ancestral sex determining system in Unidentata in previous studies, the ancestral gekkotan sex determining mechanism was ambiguous, with either ZW or XY as the potential ancestral state. Sex determining mechanism of Coleonyx was considered equivocal, possessing either an XY or ZW system, while Paroedura was polarized as a ZW system. There were still 5 independent origins of TSD within the sampled taxa.

The analysis that utilized TSD as the outgroup's ancestral sex determining mechanism reconstructed the ancestral gekkotan sex determining system as ambiguous, either TSD or XY. TSD has been estimated as the ancestral gekkotan sex determining system in previous studies, either alone [Pokorna and Kratochvil, 2009] or in a polymorphic condition [Janzen and Krenz, 2004]. The sex determining mechanism of both Coleonyx and Paroedura were also considered equivocal, possessing either an XY or ZW system.

Ancestral states within the genus Gekko were ambiguous in all reconstructions. Male heterogamety in G. gecko and G. japonicus could result from retention of ancestral male heterogamety in the genus, which would imply the recent evolution of female heterogamety in G. hokouensis. Alternatively, G. hokouensis could retain the ancestral female heterogametic condition and male heterogamety evolved twice independently, once in G. gecko and again in G. japonicus. Research that investigates the sex determining mechanisms and sex chromosomes in additional Gekko species as well as a thorough assessment of the homology among Gekko sex chromosomes would go far to resolving this ambiguity.

The results of the ancestral state reconstructions should be interpreted cautiously. Several important methodological assumptions are violated by this and other recent studies. The first assumption is that the phylogeny is accurate [Omland, 1999]. The supertree method used here should be reasonably accurate and is consistent with the recent phylogenies it was derived from. Several recent publications have used phylogenies that are not consistent in this regard. One common error is the placement of Eublepharidae as the sister taxon to the remaining Gekkota [Janzen and Krenz, 2004; Pokorna and Kra- tochvil, 2009] following several morphological studies [Kluge, 1967; Kluge, 1987] but contradicted by recent molecular phylogenies [Donnellan et al., 1999; Han et al., 2004; Townsend et al., 2004; Gamble et al., 2008a]. A second error is the placement of Pygopodidae as the sister taxon to the remaining Gekkota [Organ and Janes, 2008], a hypothesis supported by some research [Underwood, 1957; Estes et al., 1988] but contradicted by both morphological and molecular phylogenies [Kluge, 1987; Donnellan et al., 1999; Han et al., 2004; Townsend et al., 2004; Gamble et al., 2008a].

The second assumption is that all relevant taxa are included [Omland, 1999]. This is certainly violated by all of the studies, including the one presented here. This is due to the paucity of information regarding gekkotan sex determining mechanisms, with less than $3 \%$ of gecko species being characterized. Analysis of more gecko species will likely uncover many new instances of TSD, XY and $\mathrm{ZW}$ systems and subsequently increase the number of changes among systems on the phylogeny. This in turn increases the accuracy of the ancestral state reconstruction.

The third assumption is that characters are coded correctly [Omland, 1999]. This is violated on several levels. One example of this, as mentioned earlier, is the use of 'GSD' in the ancestral state reconstruction to represent species with either XY or ZW systems [Janzen and Krenz, 2004; Pokorna and Kratochvil, 2009]. Another potential error is the attribution of sex chromosomes to parthenogenetic species, e.g. Lepidodactylus lugubris and Hemidactylus vietnamensis. Because these species consist entirely of females, chromosomal heterozygosity may not be sex chromosomes but fixed heterozygosity in a particular lineage [Moritz, 1990]. A more systematic error, occurring in all of the recent publications that reconstruct the ancestral states of sex determining systems, including the present study, is the lack of information regarding homology of the sex chromosomes and sex determining systems. For example, it is known that the ZW sex chromosomes of birds, snakes and softshell turtles are not homologous [Kawai et al., 2007], that is, they have evolved from different autosomes. They could more accurately be coded as $\mathrm{ZW}_{1}, \mathrm{ZW}_{2}$ and $\mathrm{ZW}_{3}$, respectively. The discovery that $G$. hokouensis sex chromosomes are homologous to the bird ZW [Kawai et al., 2009] would suggest it to be coded as $\mathrm{ZW}_{1}$. Representing these independently derived instances of female heterogamety as simple ZW systems, therefore, dramatically underestimates the diversity of sex determining mechanisms and the subsequent number of changes that have occurred over the phylogeny. 
One can argue that these reconstructions are just heuristics that provide a rough picture of the changes that have occurred in the vertebrate sex determining system. While that may be true, a serious effort should be made to incorporate accurate homology assessments into ancestral state reconstructions not only in vertebrates but any other sexually reproducing organisms as well.

\section{Conclusions}

I have summarized current knowledge of gekkotan sex determination and have shown that at least 8 to 9 transitions among sex determining mechanisms have occurred during the last 150 million years of gekkotan evolution. The paucity of species that have been characterized, as well as a lack of knowledge concerning the homology among these mechanisms, suggests this estimate of transitions is low. It is obvious that there are many gaps remaining in our understanding of gekkotan sex determining mechanisms. We currently know the sex determining mechanisms for only 46 of the over 1,300 described gecko species and our understanding of most of those species is tenuous at best. Currently, there are no species of Carphodactylidae with known sex determining mechanism and the families Diplodactylidae, Phyllodactylidae and Sphaerodactylidae are similarly, very poorly known (fig. 2). A concerted effort should be made to examine karyotypes of a broad range of gecko species for the presence of sex chromosomes with special effort to sample representatives from across the phylogeny. Modern cytological techniques such as CGH and FISH should be used to identify sex chromosomes and subsequently assess ho- mology of presumptive sex chromosomes among related taxa. Research along these lines will undoubtedly find many more transitions among gekkotan sex determining systems. Such extraordinary diversity makes geckos excellent candidates as a model clade for studying the evolution of sex determining mechanisms in vertebrates.

New developments in cytogenetics and genomics are making it easier to study sex determination in a variety of non-model organisms. Studies of nontraditional organisms have been extremely fruitful and continue to yield many new discoveries, including: new examples of master sex determining genes [Matsuda et al., 2002; Nanda et al., 2002]; the extreme lability of sex determining systems [Ogata et al., 2008; Ross et al., 2009]; an understanding of the interplay between environmental and genetic sex determining factors [Radder et al., 2008]; and the adaptive significance of sex determining systems [Warner and Shine, 2008]. The continued development of nontraditional models is therefore important to an overall understanding of how sex determining mechanisms evolve and are maintained. As shown here, geckos can play an important role in that research.

\section{Acknowledgements}

Many thanks to A.M. Bauer, T. Ezaz, A.M. Simons and D. Zarkower for discussions about geckos and sex determination and helpful comments on the manuscript. The project described was supported by Grant Number T32DE007288 from the National Institute of Dental \& Craniofacial Research. The content is solely the responsibility of the author and does not necessarily represent the official views of the National Institute of Dental \& Craniofacial Research or the National Institutes of Health.

\section{References}

Anderson A: Captive husbandry and reproduction of the African fat-tailed gecko, $\mathrm{He}$ mitheconyx caudicinctus. Dactylus 2:12-16 (1993).

Andrews RM: Incubation temperature and sex ratio of the Veiled Chameleon (Chamaelo calyptratus). J Herpetol 39:515-518 (2005).

Aprea G, Odierna G, Capriglione T, Caputo V, Morescalchi A, Olmo E: Heterochromatin and NOR distribution in the chromosomes of six gekkonid species of the genus Phelsuma (Squamata: Gekkonidae). J Afr Zool 110: 343-349 (1996).

- Austin JJ, Arnold EN, Jones CG: Reconstructing an island radiation using ancient and recent DNA: the extinct and living day geckos (Phelsuma) of the Mascarene islands. Mol Phylogenet Evol 31:109-122 (2004).

\footnotetext{
Barske LA, Capel B: Blurring the edges in vertebrate sex determination. Curr Opin Genet Dev 18:499-505 (2008).

Bauer AM, Giri VB, Greenbaum E, Jackman TR, Dharne MS, Shouche YS: On the systematics of the gekkonid genus Teratolepis Günther, 1869: another one bites the dust. Hamadryad 32:90-104 (2008).

Bloxam Q, Tonge S: Maintenance and breeding of Phelsuma guentheri (Boulenger 1885), in Townson S, Millichamp NJ, Lucas D, Millwood AJ (eds): The Care and Breeding of Reptiles, pp 51-62 (The British Herpetological Society, London 1980).

Blumberg MS, Lewis SJ, Sokoloff G: Incubation temperature modulates post-hatching thermoregulatory behavior in the Madagascar ground gecko, Paroedura pictus. J Exp Biol 205:2777-2784 (2002).
} 
Bragg WK, Fawcett JD, Bragg TB, Viets BE: Nestsite selection in two eublepharid gecko species with temperature-dependent sex determination and one with genotypic sex determination. Biol J Linn Soc 69:319-332 (2000).

Branch WR: Chromosome morphology of some reptiles from Oman and adjacent territories. J Oman Stud 2:333-345 (1980).

Bull JJ: Evolution of Sex Determining Mechanisms (Benjamin Cummings Publishing Company, Inc., Menlo Park 1983).

Bull JJ: Temperature-dependent sex determination in reptiles: validity of sex diagnosis in hatchling lizards. Can J Zool 65:1421-1424 (1987).

Bull JJ, Vogt RC, McCoy CJ: Sex determining temperatures in turtles: a geographic comparison. Evolution 36:326-332 (1982).

Castiglia R: First chromosomal analysis for the genus Lygodactylus (Gray, 1864): the karyotype of L. picturatus (Squamata, Gekkonidae, Gekkoninae). Afr J Herpetol 53:95-97 (2004).

-Castiglia R, Garcia A, Bezerra AMR, Flores-Villela O, Gornung E: Karyotypic diversification due to Robertsonian rearrangements in Phyllodactylus lanei Smith, 1935 (Squamata, Gekkonidae) from Mexico. Rendiconti Lincei Scienze Fisiche E Naturali 20:77-82 (2009).

Castro-Franco R, Uribe-Pena Z: Dos subespecies nuevas de Phyllodactylus lanei (Sauria: Gekkonidae). An Inst Biol Ser Zool 63:113-123 (1992).

-Chaboissier MC, Kobayashi A, Vidal VI, Lutzkendorf S, van de Kant HJ, et al: Functional analysis of Sox8 and Sox9 during sex determination in the mouse. Development 131: 1891-1901 (2004).

-Charlesworth D, Charlesworth B, Marais G: Steps in the evolution of heteromorphic sex chromosomes. Heredity 95:118 (2005).

Charnov EL, Bull J: When is sex environmentally determined? Nature 266:828-830 (1977).

-Chen JC, Peng XB, Yu DW: Studies on the karyotypes of three species of the genus Gekko. Acta Herpetol Sin 5:24-29 (1986).

-Cohen MM, Huang CC, Clark HF: The somatic chromosomes of 3 lizard species: Gekko gecko, Iguana iguana and Crotaphytus collaris. Experientia 23:769-771 (1967).

-Conrad JL, Norell MA: High-resolution X-ray computed tomography of an early Cretaceous gekkonomorph (Squamata) from Öösh (Övörkhangai; Mongolia). Hist Biol 18: 405-431 (2006).

-Coomber P, Crews D, Gonzalez-Lima F: Independent effects of incubation temperature and gonadal sex on the volume and metabolic capacity of brain nuclei in the leopard gecko (Eublepharis macularius), a lizard with temperature-dependent sex determination. J Comp Neurol 380:409-421 (1997).

-Crews D: On the organization of individual differences in sexual behavior. Am Zool 38:118132 (1998).

-Cuellar O: Reproduction and the mechanism of meiotic restitution in the parthenogenetic lizard Cnemidophorus uniparens. J Morphol 133:139-166 (1971).

Cunningham CW, Omland KE, Oakley TH: Reconstructing ancestral character states: a critical reappraisal. Trends Ecol Evol 13:361366 (1998).

Darevsky IS, Kupriyanova LA, Roshchin VV: A new all-female triploid species of gecko and karyological data on the bisexual Hemidactylus frenatus from Vietnam. J Herpetol 18: 277-284 (1984).

Dawley RM: An introduction to unisexual vertebrates, in Dawley RM, Bogart JP (eds): Evolution and Ecology of Unisexual Vertebrates, pp 1-18 (The University of the State of New York, Albany, New York 1987).

De Smet WHO: Description of the orcein stained karyotypes of 27 lizard species (Lacertilia Reptilia) belonging to the families Iguanidae, Agamidae, Chameleontidae and Gekkonidae (Ascalabota). Acta Zool Pathol Antiverp 1981:35-72 (1981).

de Vosjoli P, Fast F, Repashy A: Rhacodactylus: The complete guide to their selection and care (Advanced Visions, Inc., Vista, California 2003).

Dixon JR: The systematics and distribution of lizards of the genus Phyllodactylus in North and Central America. N Mex State Univ Res Cent Sci Bull 64:1-139 (1964).

Donnellan SC, Moritz C: Genetic diversity of bisexual and parthenogenetic populations of the tropical gecko Nactus pelagicus (Lacertillia: Gekkonidae). Herpetologica 51:140154 (1995).

Donnellan SC, Hutchinson MN, Saint KM: Molecular evidence for the phylogeny of Australian gekkonoid lizards. Biol J Linn Soc 67: 97-118 (1999).

dos Santos RML, Bertolotto CEV, Pellegrino KCM, Rodrigues MT, Yonenaga-Yassuda Y: Chromosomal studies on sphaerodactyl lizards of genera Gonatodes and Coleodactylus (Squamata, Gekkonidae) using differential staining and fragile sites analyses. Cytogenet Genome Res 103:128-134 (2003).

Estes R, de Queiroz K, Gauthier J: Phylogenetic relationships within the Squamata, in Estes R, Pregill G (eds): Phylogenetic Relationships of the Lizard Families: Essays Commemorating Charles L Camp, pp 119-281 (Stanford University Press, Stanford, California 1988).

Ewert MA, Nelson CE: Sex determination in turtles: diverse patterns and some possible adaptive values. Copeia 1991:50-69 (1991).

- Ewert MA, Lang JW, Nelson CE: Geographic variation in the pattern of temperature-dependent sex determination in the American snapping turtle (Chelydra serpentina). J Zool 265:81-95 (2005).

Fitch WM: Toward defining the course of evolution: Minimal change for a specific tree topology. Syst Zool 20:406-416 (1971).

Flores D, Tousignant A, Crews D: Incubation temperature affects the behavior of adult leopard geckos (Eublepharis macularius). Physiol Behav 55:1067-1072 (1994).

Fridolfsson AK, Cheng H, Copeland NG, Jenkins NA, Liu HC, et al: Evolution of the avian sex chromosomes from an ancestral pair of autosomes. Proc Natl Acad Sci USA 95:81478152 (1998).

Gamble T, Bauer AM, Greenbaum E, Jackman TR: Evidence for Gondwanan vicariance in an ancient clade of gecko lizards. J Biogeogr 35:88-104 (2008a).

Gamble T, Bauer AM, Greenbaum E, Jackman TR: Out of the blue: a novel, trans-Atlantic clade of geckos (Gekkota, Squamata). Zool Scr 37:355-366 (2008b).

Gorman GC: The chromosomes of the Reptilia: A cytotaxonomic interpretation, in Chiarelli B. Capanna E (eds): Cytotaxonomy and Vertebrate Evolution, pp 349-424 (Academic Press, London 1973).

Gorman GC, Gress F: Sex chromosomes of a pygopodid lizard, Lialis burtonis. Experientia 26:206-207 (1970).

Graves JAM, Shetty S: Sex from W to Z: Evolution of vertebrate sex chromosomes and sex determining genes. J Exp Zool 290:449-462 (2001).

Green DM: Cytogenetics of the endemic New Zealand frog, Leiopelma hochstetteri: extraordinary supernumerary chromosome variation and a unique sex-chromosome system. Chromosoma 97:55-70 (1988).

Grismer LL: Phylogeny, taxonomy, classification, and biogeography of eublepharid geckos, in Estes R, Pregill G (eds): Phylogenetic Relationships of the Lizard Families, pp 369-469 (Stanford University Press, Stanford 1988).

Grismer LL, Haitao S, Orlov NL, Ananjeva NB: A new species of Goniurosaurus (Squamata: Eublepharidae) from Hainan Island, China. J Herpetol 36:217-224 (2002).

Han DM, Zhou KY, Wang YQ: Phylogeny of ten species of Chinese gekkonid lizard (Gekkonidae: Lacertilia) inferred from 12S rDNA sequences. Acta Zool Sin 47:139-144 (2001).

-Han D, Zhou K, Bauer AM: Phylogenetic relationships among gekkotan lizards inferred from C-mos nuclear DNA sequences and a new classification of the Gekkota. Biol J Linn Soc 83:353-368 (2004).

Harlow PS: Temperature-dependent sex determination in lizards, in Valenzuela N, Lance V (eds): Temperature-Dependent Sex Determination in Vertebrates, pp 42-52 (Smithsonian Books, Washington 2004).

Hillis DM, Green DM: Evolutionary changes of heterogametic sex in the phylogenetic history of amphibians. J Evol Biol 3:49-64 (1990).

Hodgkin J: Exploring the envelope: Systematic alteration in the sex-determination system of the nematode Caenorhabditis elegans. Genetics 162:767-780 (2002).

-Howard CJ: Breeding the flat-tailed day gecko Phelsuma laticauda at Twycross Zoo. Int Zoo Yearb 20:193-196 (1980).

Hugall AF, Foster R, Lee MSY: Calibration choice, rate smoothing, and the pattern of tetrapod diversification according to the long nuclear gene RAG-1. Syst Biol 56:543563 (2007).

Iverson JB, Brown R, Akre TS, Near TJ, Le M, et al: In search of the tree of life for turtles. Chelonian Res Monogr 4:85-106 (2007). 
-Jackman TR, Bauer AM, Greenbaum E: Phylogenetic relationships of geckos of the genus Nactus and their relatives (Squamata: Gekkonidae). Acta Herpetol 3:1-18 (2008).

Janzen FJ, Krenz JG: Phylogenetics: Which was first, TSD or GSD?, in Valenzuela N, Lance VA (eds): Temperature-Dependent Sex Determination in Vertebrates, pp 121-130 (Smithsonian Institution Press, Washington 2004).

-Janzen FJ, Phillips PC: Exploring the evolution of environmental sex determination, especially in reptiles. J Evol Biol 19:1775-1784 (2006).

Kawai A, Nishida-Umehara C, Ishijima J, Tsuda Y, Ota H, Matsuda Y: Different origins of bird and reptile sex chromosomes inferred from comparative mapping of chicken $\mathrm{Z}$ linked genes. Cytogenet Genome Res 117: 92-102 (2007).

-Kawai A, Ishijima J, Nishids C, Kosaka A, Ota H, et al: The ZW sex chromosomes of Gekko hokouensis (Gekkonidae, Squamata) represent highly conserved homology with those of avian species. Chromosoma 118:43-51 (2009).

King M: Karyotypic evolution in Gehyra (Gekkonidae: Reptilia) III: The Gehyra australis complex. Aust J Zool 31:723-741 (1983).

King M: Chromosomal evolution in the Diplodactylinae (Gekkonidae: Reptilia). I. Evolutionary relationships and patterns of change. Aust J Zool 35:507-531 (1987).

King M: Chromosomal and immunogenetic data: a new perspective on the origin of Australia's reptiles, in Olmo E (ed): Cytogenetics of Amphibians and Reptiles, pp 153-180 (Birkhäuser, Basel 1990).

King M: Chromosome change and speciation in lizards, in Atchley WR, Woodruff DS (eds): Evolution and Speciation, pp 262-285 (Cambridge University Press, Cambridge 1991).

-King M, King D: An additional chromosome race of Phyllodactylus marmoratus (Gray) (Reptilia: Gekkonidae) and its phylogenetic implications. Aust J Zool 25:667-672 (1977).

King M, Rofe R: Karyotypic variation in Australian gekko Phyllodactylus marmoratus (Gray) (Gekkonidae, Reptilia). Chromosoma 54:75-87 (1976).

Kluge AG: Higher taxonomic categories of gekkonid lizards and their evolution. Bull Am Mus Nat Hist 135:1-60 + 65 plates (1967).

Kluge AG: Cladistic relationships in the Gekkonoidea (Squamata, Sauria). Misc Publ Mus Zool Univ Mich 173:1-54 (1987).

-Kratochvil L, Kubicka L, Landova E: Does the mechanism of sex determination constrain the potential for sex manipulation? A test in geckos with contrasting sex-determining systems. Naturwissenschaften 95:209-215 (2008).

Lang JW, Andrews HV: Temperature-dependent sex determination in crocodilians. J Exp Zool 270:28-44 (1994).

Lui W: Captive husbandry and breeding of the Malaysian cat geckos, Aeluroscalabotes felinus. Reptilian 4:48-53 (1996).

Maddison WP, Maddison DR: MacClade, Analysis of Phylogeny and Character Evolution (Sinauer, Sunderland 1992).
- Maddison WP, Donoghue MJ, Maddison DR: Outgroup analysis and parsimony. Syst Zool 33:83-103 (1984).

Manilo VV: A karyosystematic study of the plate tailed geckos of the genus Teratoscincus (Sauria, Gekkonidae). Asiat Herpetol Res 5: 109-111 (1993).

Mank JE, Promislow DEL, Avise JC: Evolution of alternative sex-determining mechanisms in teleost fishes. Biol J Linn Soc 87:83-93 (2006).

- Matsubara K, Tarui H, Toriba M, Yamada K, Nishida-Umehara C, et al: Evidence for different origin of sex chromosomes in snakes, birds, and mammals and step-wise differentiation of snake sex chromosomes. Proc Natl Acad Sci USA 103:18190-18195 (2006).

Matsuda M: Sex determination in the teleost medaka, Oryzias latipes. Annu Rev Genet 39: 293-307 (2005).

- Matsuda M, Nagahama Y, Shinomiya A, Sato T, Matsuda C, et al: $D M Y$ is a Y-specific DMdomain gene required for male development in the medaka fish. Nature 417:559-563 (2002).

- Matsuda M, Sato T, Toyazaki Y, Nagahama Y, Hamaguchi S, Sakaizumi M: Oryzias curvinotus has DMY, a gene that is required for male development in the medaka, O. latipes. Zool Sci 20:159-161 (2003).

Matthey R: Nouvelle contribution á l'étude des chromosomes chez les Sauriens. Rev Suisse Zool 40:281-316 (1933).

McBee K, Bickham JW, Dixon JR: Male heterogamety and chromosomal variation in $\mathrm{Ca}$ ribbean geckos. J Herpetol 21:68-71 (1987).

McKeown S: Breeding and maintenance of the Mauritius lowland forest day gecko Phelsuma g. guimbeaui at Fresno Zoo. Int Zoo Yearb 28:116-122 (1989).

Melville J, Schulte II JA, Larson A: A molecular study of phylogenetic relationships and evolution of antipredator strategies in Australian Diplodactylus geckos, subgenus Strophurus. Biol J Linn Soc 82:123 (2004).

Moritz C: Parthenogenesis in the endemic Australian lizard Heteronotia binoei (Gekkonidae). Science 220:735-737 (1983).

Moritz C: The evolution of highly variable sex chromosomes in Gehyra purpurascens (Gekkonidae). Chromosoma 90:111-119 (1984a).

Moritz C: The origin and evolution of parthenogenesis in Heteronotia binoei (Gekkonidae). I. Chromosome banding studies. Chromosoma 89:151-162 (1984b).

-Moritz C: The population biology of Gehyra (Gekkonidae): Chromosome change and speciation. Syst Zool 35:46-67 (1986).

Moritz C: Parthenogenesis in the tropical gekkonid lizard, Nactus arnouxii (Sauria, Gekkonidae). Evolution 41:1252-1266 (1987).

Moritz C: Patterns and processes of sex chromosome evolution in gekkonid lizards (Sauria: Reptilia), in Olmo E (ed): Cytogenetics of Amphibians and Reptiles, pp 205-219 (Birkhäuser, Basel 1990).

Moritz C, Adams M, Donnellan S, Baverstock P: The origin and evolution of parthenogenesis in Heteronotia binoei (Gekkonidae): Genetic diversity among bisexual populations. Copeia 333-348 (1990).
Muller HJ: A gene for the fourth chromosome of Drosophila. J Exp Zool 17:325-336 (1914).

Murphy RW: A new genus and species of Eublepharine gecko (Sauria: Gekkonidae) from Baja California, Mexico. Proc Calif Acad Sci 40:87-92 (1974).

Myers A: The maintenance and breeding of Sarasincs gecko Rhacodactylus sarasinorum Roux. Reptilian 5:34-36 (1997).

Nakamura K: Studies on reptilian chromosomes III: Chromosomes of some geckos. Cytologia 3:156-168 (1932).

Nanda I, Kondo M, Hornung U, Asakawa S, Winkler C, et al: A duplicated copy of $D M R T 1$ in the sex-determining region of the Y chromosome of the medaka, Oryzias latipes. Proc Natl Acad Sci USA 99:1177811783 (2002).

Nettmann HK, Rykena S: Verhaltens- und fortpflanzungsbiologische Notizen über kanarische und nordafrikanische TarentolaArten. Bonn Zool Beitr 36:287-305 (1985).

Odierna G, Aprea G, Capriglione T, Caputo V, Olmo E: Chromosomal diversification in the gekkonid Tarentola mauritanica (Reptilia, Gekkonidae). Boll Zool 61:325-330 (1994).

- Ogata M, Hasegawa Y, Ohtani H, Mineyama M, Miura I: The ZZ/ZW sex-determining mechanism originated twice and independently during evolution of the frog, Rana rugosa. Heredity 100:92-99 (2008).

Ohno S: Sex Chromosomes and Sex-linked Genes (Springer Verlag, Berlin 1967).

Omland KE: The assumptions and challenges of ancestral state reconstructions. Syst Biol 48: 604-611 (1999).

Organ CL, Janes DE: Evolution of sex chromosomes in Sauropsida. Integr Comp Biol 48: 512-519 (2008).

Osadnik G: Untersuchungen zur Reproduktionsbiologie des madagassischen Taggeckos Phelsuma dubia, p 311 (Ruhr-Universität Bochum, 1987).

-Ota H, Hikida T, Matsui M, Mori A: Karyotypes of two species of the genus Cyrtodactylus (Squamata: Gekkonidae) from Sarawak, Malaysia. Caryologia 45:43-49 (1992).

Ota H, Hikida T, Nabhitabhata J, Panha S: Cryptic taxonomic diversity in two broadly distributed lizards of Thailand (Mabuya macularia and Dixonius siamensis) as revealed by chromosomal investigations (Reptilia: Lacertilia). Nat Hist J Chulalongkorn Univ 1:1-7 (2001).

Pokorna M, Kratochvil L: Phylogeny of sex-determining mechanisms in squamate reptiles: are sex chromosomes an evolutionary trap? Zool J Linn Soc 156:168-183 (2009).

Qin XM, Zeng ZH, Liang YN: Genetic variation and differentiation of Gekko gecko from different populations. Zool Res 28:286-290 (2007).

Radder RS, Quinn AE, Georges A, Sarre SD, Shine R: Genetic evidence for co-occurrence of chromosomal and thermal sex-determining systems in a lizard. Biol Lett 4:176-178 (2008).

Rhen T, Lang JW: Phenotypic plasticity for growth in the common snapping turtle: effects of incubation temperature, clutch, and 
their interaction. Am Nat 146:726-747 (1995).

Röll B, von Düring MUG: Sexual characteristics and spermatogenesis in males of the parthenogenetic gecko Lepidodactylus lugubris (Reptilia, Gekkonidae). Zoology 111:385400 (2008).

Ross JA, Urton JR, Boland JE, Shapiro MD, Peichel CL: Turnover of sex chromosomes in the stickleback fishes (Gasterosteidae). PLoS Genet 5:1-12 (2009).

Sanderson MJ: r8s 1.71 (Davis, California 2006).

-Sarre SD, Georges A, Quinn A: The ends of a continuum: genetic and temperature-dependent sex determination in reptiles. Bioessays 26:639-645 (2004).

Seipp R, Henkel FW: Rhacodactylus: Biology, Natural History \& Husbandry (Edition Chimaira, Frankfurt 2000).

Seufer H, Kaverkin Y, Kirschner A: The Eyelash Geckos: Care, Breeding and Natural History (Kirschner and Seufer Verlag, Karlsruhe 2005).

-Shimizu Y, Shibata N, Yamashita M: Spermiogenesis without preceding meiosis in the hybrid medaka between Oryzias latipes and $O$. curvinotus. J Exp Zool 279:102-112 (1997).

Shine R: Why is sex determined by nest temperature in many reptiles? Trends Ecol Evol 14: 186-189 (1999).

-Shine R, Elphick MJ, Donnellan S: Co-occurrence of multiple, supposedly incompatible modes of sex determination in a lizard population. Ecol Lett 5:486-489 (2002).

- Shine R, Warner DA, Radder R: Windows of embryonic sexual lability in two lizard species with environmental sex determination. Ecology 88:1781-1788 (2007).

Shoemaker CM, Crews D: Analyzing the coordinated gene network underlying temperature-dependent sex determination in reptiles. Semin Cell Dev Biol 20:293-303 (2009).

Solleder E, Schmid M: XX/XY sex chromosomes in Gekko gecko (Sauria, Reptilia). Amphibia Reptilia 5:339-345 (1984).

Sonnemann N: Captive breeding of the giant cave gecko, Pseudothecadactylus lindneri lindneri (Cogger 1975). Dactylus 3:103-114 (1998).

Strasburg JL, Kearney M: Phylogeography of sexual Heteronotia binoei (Gekkonidae) in the Australian arid zone: climatic cycling and repetitive hybridization. Mol Ecol 14: 2755-2772 (2005).

Swofford D: PAUP*. Phylogenetic Analysis Using Parsimony (*and other methods) (Sinauer, Sunderland 2002).

- Tautz D, Arctander P, Minelli A, Thomas RH, Vogler AP: A plea for DNA taxonomy. Trends Ecol Evol 18:70-74 (2003).
Thorogood J, Whimster IW: The maintenance and breeding of the leopard gecko Eublepharis macularius as a laboratory animal. Int Zoo Yearb 19:74-78 (1979).

Toda M, Hikida T, Ota H: Discovery of sympatric cryptic species within Gekko hokouensis (Gekkonidae: Squamata) from the Okinawa Islands, Japan, by use of allozyme data. Zool Scr 30:1-11 (2001).

Toda M, Okada S, Hikida T, Ota H: Extensive natural hybridization between two geckos, Gekko tawaensis and Gekko japonicus (Reptilia: Squamata), throughout their broad sympatric area. Biochem Genet 44:1-17 (2006).

Toda M, Sengoku S, Hikida T, Ota H: Description of two new species of the genus Gekko (Squamata: Gekkonidae) from the Tokara and Amami island groups in the Ryukyu Archipelago, Japan. Copeia 2008:452-466 (2009).

Tokunaga S: Temperature-dependent sex determination in Gekko japonicus (Gekkonidae, Reptilia). Dev Growth Differ 27:117-120 (1985).

Tousignant A, Crews D: Incubation temperature and gonadal sex affect growth and physiology in the leopard gecko (Eublepharis macularius), a lizard with temperature-dependent sex determination. J Morphol 224:159-170 (1995).

Townsend TM, Larson A, Louis E, Macey JR: Molecular phylogenetics of Squamata: The position of snakes, amphisbaenians, and dibamids, and the root of the squamate tree. Syst Biol 53:735-757 (2004).

Tytle TL: Husbandry of captive day geckos (Phelsuma): Past, present, and future, in Murphy JB, Adler K, Collins JT (eds): Captive Management and Conservation of Amphibians and Reptiles, vol 11, pp 307-310 (SSAR, Lawrence 1994).

Uetz P: The TIGR Reptile Database. http://www. reptile-database.org/, vol 2008 (2009).

Underwood G: On lizards of the family Pygopodidae. A contribution to the morphology and phylogeny of the Squamata. J Morphol 100:207-268 (1957).

Valenzuela N: Temperature-dependent sex determination, in Deeming DC (ed): Reptilian Incubation: Environment, Evolution and Behaviour (Nottingham University Press, Nottingham 2004).

Valenzuela N: Relic thermosensitive gene expression in a turtle with genotypic sex determination. Evolution 62:234-240 (2008).

Valenzuela N, Shikano T: Embryological ontogeny of aromatase gene expression in Chrysemys picta and Apalone mutica turtles: comparative patterns within and across temperature-dependent and genotypic sexdetermining mechanisms. Dev Genes Evol 217:55-62 (2007).
Valenzuela N, Adams DC, Janzen FJ: Pattern does not equal process: Exactly when is sex environmentally determined? Am Nat 161: 676-683 (2003).

Valleley EMA, Cartwright EJ, Croft NJ, Markham AF, Coletta PL: Characterisation and expression of Sox 9 in the leopard gecko, Eublepharis macularius. J Exp Zool 291:8591 (2001).

Vences M, Thomas M, Van der Meijden A, Chiari Y, Vieites DR: Comparative performance of the 16S rRNA gene in DNA barcoding of amphibians. Front Zool 5:1-12 (2005).

Vidal N, Hedges SB: The molecular evolutionary tree of lizards, snakes, and amphisbaenians. C R Biol 332:129-139 (2009).

Viets BE, Tousignant A, Ewert MA, Nelson CE, Crews D: Temperature-dependent sex determination in the leopard gecko, Eublepharis macularius. J Exp Zool 265:679-683 (1993).

Viets BE, Ewert MA, Talent LG, Nelson CE: Sexdetermining mechanisms in squamate reptiles. J Exp Zool 270:45-56 (1994).

Volobouev V, Pasteur G: Presumptive sex chromosomes of a unisexual homomorphic species of lizards, Lepidodactylus lugubris. Heredity 60:463-467 (1988).

Wagner E: Gecko husbandry and reproduction, in Murphy JB, Collins JT (eds): Reproductive Biology and Diseases of Captive Reptiles, pp 115-117 (Society for the Study of Amphibians and Reptiles, Lawrence 1980a).

Wagner E: Temperature-dependent sex determination in a gekko lizard. Q Rev Biol 55:21 (1980b).

Warner DA, Shine R: The adaptive significance of temperature-dependent sex determination in a reptile. Nature 451:566-568 (2008).

Western PS, Sinclair AH: Sex, genes, and heat: Triggers of diversity. J Exp Zool 290:624-631 (2001).

Wu G, Zhao E: Studies on karyotypes of Gekko gecko and Gekko subpalmatus. Acta Herpetol Sin 3:61-64 (1984).

Yoshida M, Itoh M: Karyotype of the gecko, Gekko japonicus. Chrom Inf Serv 17:29-31 (1974).

Zarkower D: Establishing sexual dimorphism: Conservation amidst diversity? Nat Rev Genet 2:175-185 (2001).

Zeng XM, Wang YZ, Liu ZJ, Fang ZL, Wu GF, et al: Karyotypes of Chinese species of the genus Teratoscincus (Gekkonidae). Jpn J Herpetol 17:139-144 (1998).

Zhou K, Liu YZ, Li DJ: Three new species of Gek$k o$ and remarks on Gekko hokouensis (Lacertiformes, Gekkonidae). Smithson Herpetol Inf Serv 1989:1-12 (1989). 